\title{
Numerical simulation of formation and preservation of Ningwu ice cave, Shanxi, China
}

\author{
S. Yang ${ }^{1,2,3}$ and Y. Shi ${ }^{2,3}$ \\ ${ }^{1}$ State Key Laboratory of Continental Tectonics and Dynamics, Institute of Geology, Chinese Academy of Geological \\ Sciences, Beijing, 100037, China \\ ${ }^{2}$ Key Laboratory of Computational Geodynamics, Chinese Academy of Sciences, Beijing, 10049, China \\ ${ }^{3}$ University of Chinese Academy of Sciences, Beijing, 100049, China \\ Correspondence to: Y. Shi (shiyl@ucas.ac.cn)
}

Received: 25 January 2015 - Published in The Cryosphere Discuss.: 14 April 2015

Revised: 3 September 2015 - Accepted: 4 October 2015 - Published: 22 October 2015

\begin{abstract}
Ice caves exist in locations where annual average air temperature is higher than $0^{\circ} \mathrm{C}$. An example is Ningwu ice cave, Shanxi Province, the largest ice cave in China. In order to quantitatively investigate the mechanism of formation and preservation of the ice cave, we use the finite-element method to simulate the heat transfer process at this ice cave. There are two major control factors. First, there is the seasonal asymmetric heat transfer. Heat is transferred into the ice cave from outside very inefficiently by conduction in spring, summer and fall. In winter, thermal convection occurs that transfers heat very efficiently out of the ice cave, thus cooling it down. Secondly, ice-water phase change provides a heat barrier for heat transfer into the cave in summer. The calculation also helps to evaluate effects of global warming, tourists, colored lights, climatic conditions, etc. for sustainable development of the ice cave as a tourism resource. In some other ice caves in China, managers have installed airtight doors at these ice caves' entrances with the intention of "protecting" these caves, but this in fact prevents cooling in winter and these cave ices will entirely melt within tens of years.
\end{abstract}

\section{Introduction}

An ice cave is a type of natural cave that contains significant amounts of perennial ice. An ice cave is a rare phenomenon. Among the best known are Eisriesenwelt ice cave, Austria (May et al., 2011; Obleitner and Spötl, 2011; Schöner et al., 2011); Dobšináice cave, Slovakia (Bella, 2006; Lalkovič,
1995); Scărisoara ice cave, Romania (Holmlund et al., 2005; Perşoiu et al., 2011); and Monlesi ice cave, Switzerland (Luetscher et al., 2007, 2008). Eisriesenwelt ice cave is the largest in the world. Dobšiná ice cave is also huge, with an ice volume of over $110000 \mathrm{~m}^{3}$ (Bella, 2006). In China, more than 10 ice caves have been found, including Ningwu, Wudalianchi, Taibaishan, Cuihuashan, Baiyizhai and Shennongjia ice caves.

Studies of ice caves began as early as 1861 (Peters, 1861). In recent decades, in the context of interest in global climate change, six international conferences on ice caves have been held, with the reconstruction of regional ancient climate change as an important topic for discussion (Laursen, 2010). Several articles have reported seasonal air temperature oscillations of several degrees Celcius from ventilated cave systems (Roberts et al., 1998; Lacelle et al., 2004; Johnson et al., 2006). Therefore, to evaluate the impact of changing climatic conditions on cave environments, a better explanation of subsurface heat and mass transfers is necessary (Luetscher et al., 2008). Moreover, ice caves are tourism resources. A better explanation of subsurface heat and mass transfers could help to manage ice caves more scientifically.

In the past, empirical calibrations have been performed to determine the spatial and temporal distribution of cave air temperature as a function of the external atmospheric conditions (de Freitas and Littlejohn, 1987; de Freitas et al., 1982). In temperate karst environments, explanation of the survival of subsurface ice accumulations represents probably the most severe test for models of the magnitude and direction of heat and mass transfers induced by cave air circula- 

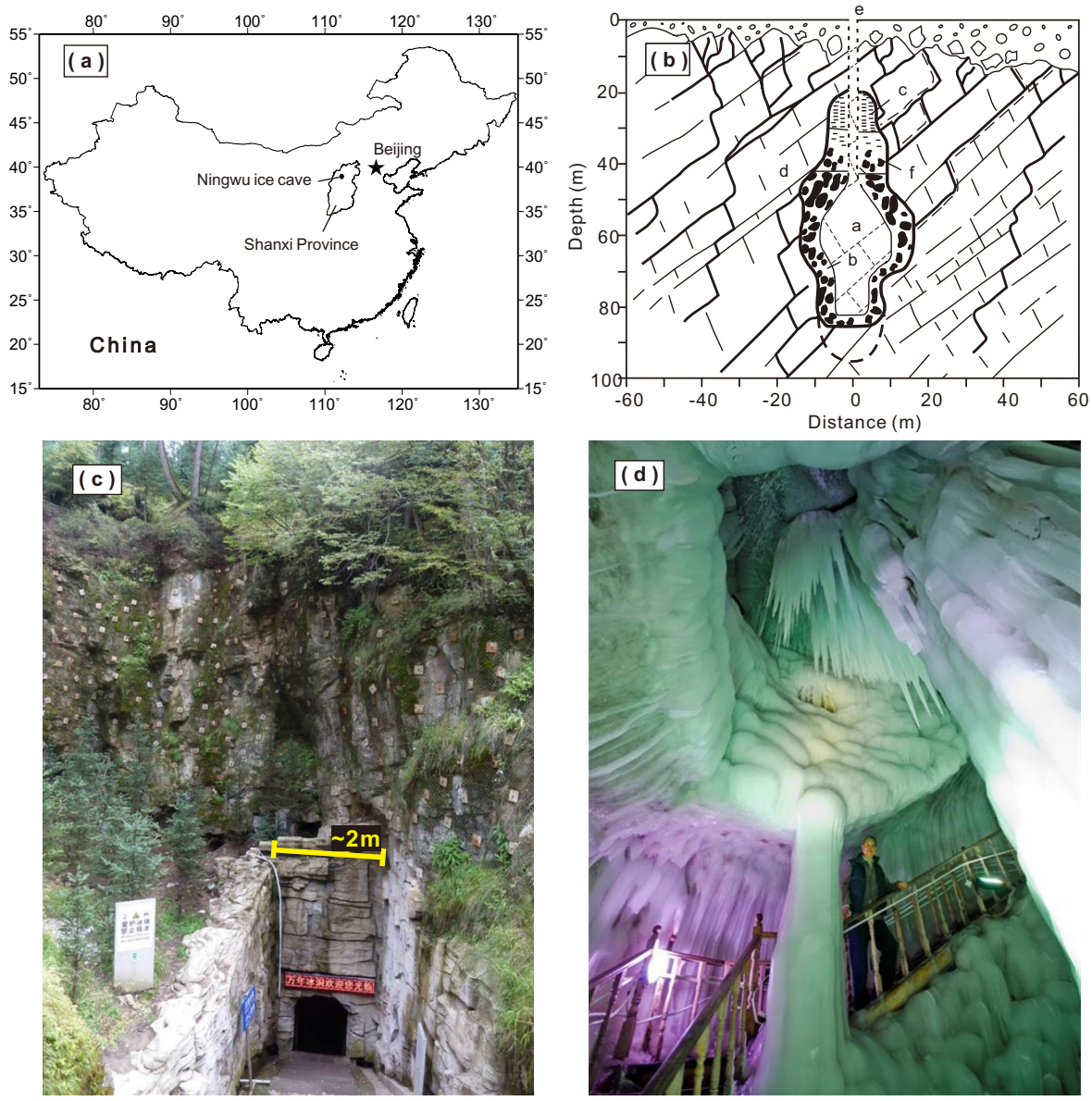

Figure 1. Location (a), cross section (b), entrance (c) and inside (d) of Ningwu ice cave. In (b): (a) the main cavern, (b) block ice, (c) layered ice, (d) limestone, (e) the entrance, and (f) a fracture.

tion (Luetscher et al., 2008). In mathematics and engineering, the finite-element method (FEM) and the finite-difference method (FDM) are popular for finding approximate solutions for partial differential equations. We have not found any study in which these numerical techniques are applied to ice caves.

In China, ice cave studies started only recently, after 1998, when Ningwu ice cave was found. Although Ningwu ice cave has been widely reported during the past decade (Gao et al., 2005; Meng et al., 2006), little was known about the processes controlling the formation and preservation of perennial subsurface ice deposits under changing climate conditions (Chen, 2003). We attempt to apply FEM to simulate the energy fluxes of Ningwu ice cave and then quantitatively interpret the formation and preservation mechanism of the ice deposit in Ningwu ice cave. Some suggestions are given to manage Ningwu ice cave.

\section{Study site}

Ningwu ice cave $\left(38^{\circ} 57^{\prime} \mathrm{N}, 112^{\circ} 10^{\prime} \mathrm{E} ; 2121 \mathrm{~m}\right.$ a.s.l. (above sea level); Fig. 1a) is the largest ice cave ever found in China. Located on the northern slopes of Guancen Mountain, Ningwu County, Shanxi Province, it is known to local people as "the ten-thousand-years ice cave". The surrounding rock consists of Ordovician Majiagou limestone, dolomitic limestone, argillaceous dolomite and thin brecciated limestone which is locally densely fractured (Shao et al., 2007). A geophysical exploration (using magnetotelluric measurement) was carried out by Shao et al. (2007) in order to investigate the shape of the ice cave, and they obtained the vertical cross section of the ice cave. The cave space is about $85 \mathrm{~m}$ depth. The widest part is in the middle, with a width of $20 \mathrm{~m}$.

The ice cave is a major tourist attraction. From May to October, about 1000 visitors enter the cave per day. The ice cave has only one entrance (Fig. 1c), and has wooden spiral stairs leading to a bowling-pin-shaped room. Ice covers the host rock almost completely. Ice stalactites and ice stalagmites (Fig. 1d) can be seen in all parts of the cave. 
The outside of the ice cave has a temperate climate. The external mean air temperature from June to September is about $14.6{ }^{\circ} \mathrm{C}$, and the mean annual air temperature is $2.3^{\circ} \mathrm{C}$ (Meng et al., 2006). The daily temperature from 1957 to 2008 is obtained from Wuzhai meteorological station (about $320 \mathrm{~m}$ lower than Ningwu ice cave), which is the nearest station to the ice cave. We averaged observational air temperature at Wuzhai station to obtain the annual temperature and then derived the mean annual temperature at Wuzhai station. We calculated the difference between the average annual air temperature at Ningwu ice cave and that at Wuzhai station. After reducing the annual temperature at Wuzhai station by the difference, we then obtain the annual temperature variation outside the ice cave (Fig. 2).

\section{Qualitative analysis}

There are different hypotheses about the preservation mechanism of ice deposit in Ningwu ice cave. Chen (2003) proposed that the existence of a "cold source" led to the negative geothermal anomaly which preserves the ice deposit. Meng et al. (2006) ascribed the ice deposit to multiple factors, including geographical location, the "icehouse effect", the "chimney effect", and the "thermal effect" produced by the ice deposit and the "millennial volcano". However, they did not provide any further details about these factors. Gao et al. (2005) analyzed two aspects: terrain and climate. Because this region has a long, cold winter and a short, cool summer, they considered that far more cold air than warm air entered the region and thus the ice cave stayed cold over the year.

Subsurface temperature usually increases with depth at a geothermal gradient of about $1.0-3.0^{\circ} \mathrm{C}(100 \mathrm{~m})^{-1}$ (Hu et al., 2001). The notion that there is a permanent "cold source" underground is unfounded. Even if a cold region had somehow formed, it would be heated up by the geothermal flux from underneath in geological time. Reversal of geotherms can occur in the presence of the advective heat transfer due to crustal movement or groundwater flow (Shi and Wang, 1987). A reversal of geotherms can also occur from transient changes in surface temperature and be induced by steep topography (Gruber et al., 2004). However, the outside of Ningwu ice cave has a temperate climate. It is hard to preserve an ice cave in a temperate climate without a sustainable cooling mechanism. In the presence of a geothermal gradient, the host rock continuously transfers heat to the ice cave, so there must be a sustainable mechanism to remove the heat from underneath and ensure the maintenance of the ice cave.

The temperature outside the ice cave undergoes annual cyclic variations: in spring, summer and fall, it is higher than the internal temperature, but in winter it is lower. As Ningwu ice cave is bowling-pin-shaped with only an opening in the upper part, cold air in spring, summer, and fall is heavy and sinks into the cave and thus will not produce natural thermal convection. Conduction is the main form of heat transfer

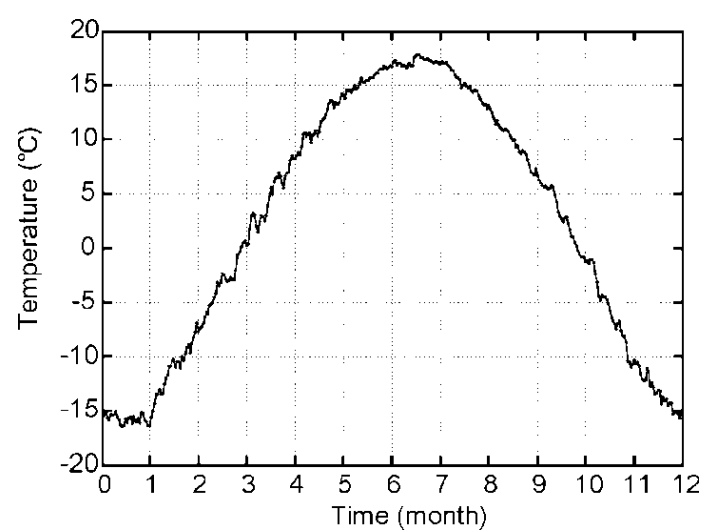

Figure 2. Yearly variation in external air temperature of Ningwu ice cave.

from the outside down to the ice cave, and from the host rock due to the terrestrial heat flows. Thermal conductivities are not high for either rock or air, and the conductive heat transfer efficiency is very low, so the heat transferred to the ice cave in the three seasons is quite limited. In winter, the temperature is low inside the ice cave but even lower outside. The air in the ice cave is lighter and air outside the cave entrance is heavier. It could thus become gravitationally unstable, and thermal convection could occur. The external cold air flows into the cave to cool it down, and it removes the heat transferred into the cave from the host rock, as well as the heat transferred into the cave through the entrance in spring, summer and fall. Since convective heat transfer is much more efficient than conduction, the heat transferred out of the cave in the winter months is enough to balance the heat that transferred into the cave year-round.

Ice melting into water absorbs a lot of latent heat. The melting heat of ice is $334 \mathrm{~kJ} \mathrm{~kg}^{-1}$ and the specific heat of limestone is about $0.84 \mathrm{~kJ} \mathrm{~kg}^{-1} \mathrm{~K}^{-1}$. During summer, much of the heat transferred to cave is consumed to melt the ice to $0{ }^{\circ} \mathrm{C}$ water. Therefore, ice-water phase change can reduce the rate of temperature rise. Similarly, when the ambient temperature decreases, ice-water phase change can reduce the rate of temperature decrease. Therefore, ice-water phase change in the ice cave can "buffer" the temperature change. A small amount of ice melting near the cave entrance effectively prevents the heat from being transferred into the deep cave. When the surface water flows into the ice cave from the entrance, the ice cave temperature will not significantly increase.

The calculated energy balance of some cave ices (e.g., Eisriesenwelt ice cave) is largely determined by the input of long-wave radiation originating at the host rock surface (Obleitner and Spötl, 2011). Ice covers the host rock in Ningwu cave almost completely. Therefore, we suggest that long-wave radiation originating at the host rock surface is not a predominant factor in the processes of the formation and preservation of ice deposit in Ningwu ice cave. 
In summary, the air and the host rock transfer heat to the ice cave, making the cave temperature rise in spring, summer and fall. In winter, the heat convection of air makes the heat flow out of the cave, lowering the cave temperature. However, the ice-water phase transition effect occurs all year round. The annual heat budget of income and output is balanced, so the cave will be in a cyclic state with very small temperature fluctuations, and the average temperature is always lower than $0^{\circ} \mathrm{C}$; thus ice bodies in the ice cave can be preserved.

Snow crystals (or hoar frost) are single crystals of ice that grow from water vapor. If humidity enters a cave and then forms an ice deposit, snow crystals could be discovered (Kenneth, 2005). However, it is difficult to find snow crystals in Ningwu ice cave. No clear traces of water or snow entering the cave through its entrance could be found. However, karstified carbonate rock is heterogeneous and highly fractured, and with a permeability developed such that water movement occurs below the surface (Fairchild and Baker, 2012). In summary, we infer that most of the ice in the cave is formed by freezing of infiltration water.

Water and ice are in a dynamic equilibrium state. Water infiltrates into Ningwu ice cave throughout the year and forms ice. Ice at the bottom of Ningwu ice cave is thawed under geothermal flow, and the produced water infiltrates into areas beneath Ningwu ice cave. Ice stalactites and ice stalagmites (Fig. 1d) can be seen in all parts of Ningwu ice cave. This can verify the former process, but no directly observational evidence supports the latter process.

$R a$, the Rayleigh number, is a dimensionless number associated with buoyancy-driven flow. When $R a$ is below a critical value for that fluid, heat transfer is primarily in the form of conduction; when it exceeds the critical value, heat transfer is primarily in the form of convection. $\mathrm{Nu}$, the Nusselt number, is a dimensionless number, defined as the ratio of convection heat transfer to pure conduction heat transfer under the same conditions. The process of ice build-up in Ningwu ice cave is a self-regulating process. If too much ice accumulates in Ningwu ice cave, then the cavity will become small. Thus, $R a$ and $N u$ will be reduced, meaning the freezing efficiency becomes low. Some of the cave ice will be thawed, and the cavity will become large, and thus $\mathrm{Ra}$ and $\mathrm{Nu}$ will be increased; this means that the freezing efficiency will become high, and therefore ice will be accumulated in Ningwu ice cave.

\section{Principle of simulation}

\subsection{Basic ideas of simulation}

Two heat transmission mechanisms must be taken into account to explain the preservation of ice mass in ice cave, namely thermal conduction and convection. The phase change must also be considered. The heat conduction equa- tion can be used to describe the heat-conducting process, while for the convection process, due to the complicated geometrical shape structure inside the ice cave and complex varying boundary conditions, the convection pattern of air and its thermal consequences are hard to determine exactly. In view of this, a widely used, simplified method is applied in this study: evaluation of $\mathrm{Nu}$ and solving the conductive equation by introducing an equivalent thermal conductivity of the convecting air. In the case of an upright circular tube, the relation between the temperature difference of the top and the bottom and $\mathrm{Nu}$ can be determined by adopting the experimental relation of natural thermal convection. The enthalpy method can be adopted to calculate the phase change.

In every time step of our modeling process, it is judged whether air convection occurs based on the temperature difference between the top and the bottom of the cave. If there is no convection, the simple conduction problem will be solved, while if convection occurs, an effective conductivity is used in the thermal equation.

\subsection{Equation and physical parameters}

The heat conduction equation is

$c \rho \frac{\partial T}{\partial t}=k \nabla^{2} T$

where $c$ is the specific heat, $\rho$ is density, $T$ is temperature (unknown number), $t$ is time and $k$ is thermal conductivity. For the convective heat transfer process, an equivalent thermal conductivity is used in Eq. (1) based on $\mathrm{Nu}$.

The enthalpy method is used to calculate the phase change process. A physical quantity enthalpy, $H$, is introduced in Eq. (2), where $T_{\mathrm{r}}$ is an arbitrary lower-temperature limit. For phase change, enthalpy $H$ can be determined by Eqs. (3)(5) (Lewis, 1996); in particular, $\left(T_{\mathrm{S}}, T_{1}\right)$ is the phase change range. Water-ice phase change occurs at $0^{\circ} \mathrm{C}$. But in the numerical model, it is necessary to give a phase change range.

$$
\begin{aligned}
H(T)= & \int_{T_{\mathrm{r}}}^{T} \rho c(T) \mathrm{d} T, \\
H(T)= & \int_{T_{\mathrm{r}}}^{T} \rho c_{\mathrm{S}}(T) \mathrm{d} T \quad T \leq T_{\mathrm{s}}, \\
H(T)= & \int_{T_{\mathrm{r}}}^{T_{\mathrm{s}}} \rho c_{\mathrm{S}}(T) \mathrm{d} T+\int_{T_{\mathrm{s}}}^{T}\left[\rho\left(\frac{\mathrm{d} L}{\mathrm{~d} T}\right)+\rho c_{\mathrm{f}}(T)\right] \mathrm{d} T \\
& T_{\mathrm{s}}<T<T_{1}, \quad
\end{aligned}
$$


Table 1. Relative material parameters.

\begin{tabular}{llll}
\hline Material & $\begin{array}{l}\text { Thermal } \\
\text { conductivity } \\
\mathrm{W} \mathrm{m}^{-1} \mathrm{k}^{-1}\end{array}$ & $\begin{array}{l}\text { Density } \\
\mathrm{kg} \mathrm{m}^{-3}\end{array}$ & $\begin{array}{l}\text { Specific } \\
\text { heat } \\
\mathrm{kJ} \mathrm{kg}^{-1} \mathrm{~K}^{-1}\end{array}$ \\
\hline Limestone & 2.7 & 2500 & 0.84 \\
Ice & 2.23 & 916.5 & 2.05 \\
Mixture & 2.465 & 1708.25 & 1.445 \\
Air & 0.0243 & 1.293 & 1.005 \\
Water & 0.58 & 1000 & 4.2 \\
\hline
\end{tabular}

$$
\begin{aligned}
H(T) & =\int_{T_{\mathrm{r}}}^{T_{\mathrm{s}}} \rho c_{\mathrm{s}}(T) d T+\rho L+\int_{T_{\mathrm{s}}}^{T_{\mathrm{l}}} \rho c_{\mathrm{f}}(T) \mathrm{d} T \\
& +\int_{T_{1}}^{T} \rho c_{1}(T) \mathrm{d} T \quad T \geq T_{1},
\end{aligned}
$$

where $c_{\mathrm{S}}$ is the specific heat in solid phase, $c_{1}$ is the specific heat in liquid phase, $c_{\mathrm{f}}$ is the specific heat in solid-liquid mixing state and $L$ is the latent heat. There are many ways to calculate heat capacity (Lewis and Roberts, 1987). The simple and accurate backward differentiation formula (Lewis and Roberts, 1987; Morgan et al., 1978) is adopted here, as expressed in Eq. (6), where $(n)$ and $(n-1)$ stand for the time step. Equation (6) can be substituted into the heat equation along with the relevant material parameters for calculation.

$(c \rho)^{(n)}=\left(\frac{\mathrm{d} H}{\mathrm{~d} T}\right)^{(n)}=\frac{H^{(n)}-H^{(n-1)}}{T^{(n)}-T^{(n-1)}}$

Relevant materials include limestone, ice, ice-limestone mixture, air and water. Parameters of these materials are listed in Table 1. The physical parameter of ice-limestone mixture is taken as the arithmetic mean of those of ice and limestone. We assume that the ice body exists when temperature is below $-0.1{ }^{\circ} \mathrm{C}$, and that an ice-water mixture exists between -0.1 and $0.1{ }^{\circ} \mathrm{C}$, and this becomes water when the temperature exceeds $0.1^{\circ} \mathrm{C}$. The ratio of ice and water in the mixture is linear to the temperature within the phase change range, and so are the physical parameters. The latent heat $L$ of the ice-water phase change is $334 \mathrm{~kJ} \mathrm{~kg}^{-1}$.

\subsection{Equivalent thermal conductivity}

When the convection occurs, heat transfer is $N u$ times greater than the conductive heat transfer under the same conditions. In other words, an equivalent thermal conductivity can be introduced, which is $\mathrm{Nu}$ times greater than the air thermal conductivity (Schmeling and Marquart, 2014). $N u$ is related to the temperature difference of air at the top and the bottom of the cave, to physical properties (e.g., viscosity and conductivity of air), and also to the geometry of the cave.
Table 2. $G r$ number and constant for different flow types (Yang and Tao, 2006).

\begin{tabular}{llll}
\hline Flow state & $\begin{array}{l}\text { Coefficient } \\
C\end{array}$ & $\begin{array}{l}\text { Index } \\
n\end{array}$ & $\begin{array}{l}\text { Gr application } \\
\text { range }\end{array}$ \\
\hline Laminar flow & 0.59 & $1 / 4$ & $1.43 \times 10^{4}-3 \times 10^{9}$ \\
Transitional flow & 0.0292 & 0.39 & $3 \times 10^{9}-2 \times 10^{10}$ \\
Turbulent flow & 0.11 & $1 / 3$ & $>2 \times 10^{10}$ \\
\hline
\end{tabular}

Ningwu ice cave can be approximated by an upright circular tube. For such a tube, $N u$ can be calculated based on fluid thermodynamics studies. When Eq. (7) is satisfied (Sparrow and Gregg, 1956; Yang and Tao, 2006), which is the case for Ningwu ice cave, the natural convection heat transfer experimental relation (Sparrow and Gregg, 1956; Incropera et al., 2011) is expressed as Eq. (8).

$d / h \geq 35 / G r^{1 / 4}$

$N u_{\mathrm{m}}=C(G r \cdot \operatorname{Pr})_{\mathrm{m}}^{n}$

In Eqs. (7) and (8), $d$ and $h$ are respectively the diameter and height of a circular tube; $N u_{m}$ is the Nusselt number, where subscript " $m$ " represents the arithmetic mean temperature of the boundary layer; $\mathrm{Gr}$ is the Grashof number, which approximates the ratio of the buoyancy to viscous force acting on a fluid; $P r$ is the Prandtl number; and $C$ and $n$ are constants, the values of which are shown in Table 2.

The Prandtl number, a dimensionless number, is defined as the ratio of momentum diffusively to thermal diffusively. $\operatorname{Pr}$ is dependent only on the fluid material. For air, $\operatorname{Pr}$ is 0.7 . The Grashof number is

$G r=g \beta \Delta T l^{3} / v^{2}$,

where $g$ is the acceleration of gravity, $\beta$ is the coefficient of cubical expansion, $\Delta T$ is a temperature difference, $l$ is a characteristic length and $v$ is the coefficient of kinematic viscosity. The values are $g=9.8 \mathrm{~m} \mathrm{~s}^{-2}, \beta=3.67 \times 10^{-3} \mathrm{k}^{-1}$, $l=80 \mathrm{~m}, v=13.30 \times 10^{-6} \mathrm{~m}^{2} \mathrm{~s}^{-1}$ and are substituted into Eq. (9) to obtain

$G r=1.041 \times 10^{14} \Delta T$.

According to Eq. (10), when the temperature difference is only $10^{-3}{ }^{\circ} \mathrm{C}, \mathrm{Gr}$ can reach $1.041 \times 10^{11}$. According to Table 2 , we infer that natural convection will occur and the flow state of air is a turbulent flow when the temperature is higher inside than outside the ice cave. Equation (11), relating $\mathrm{Nu}$ to the temperature difference, can be obtained when relevant parameters are substituted into Eq. (8).

$N u=11000(0.0740 \Delta T)^{1 / 3}$

Even if Eq. (7) is not satisfied, corresponding experimental relations can also be found in the literature (Cebeci, 1974; Minkowycz and Sparrow, 1974; Yang and Tao, 2006). 


\subsection{Models and boundary conditions}

The rectangular Eulerian computational domain corresponds to a physical domain of $300 \times 190 \mathrm{~m}$ on the basis of the ice cave cross section (Fig. 1b). There are 32825 nodes and 64986 elements involved in drawing the FEM grid. The grids for the ice body and the interior air are denser.

The mean value of the geothermal gradient of the Lvliang highland area, where Ningwu ice cave is located, is $2.02{ }^{\circ} \mathrm{C}(100 \mathrm{~m})^{-1}(\mathrm{Li}, 1996)$. The mean value of the geothermal gradient of the low-lying Linxian and Liulin areas in Shanxi Province is $2.20^{\circ} \mathrm{C}(100 \mathrm{~m})^{-1}$ (Hu et al., 2001). We take the normal geothermal gradient value of $2.0^{\circ} \mathrm{C}(100 \mathrm{~m})^{-1}$ in the model. The temperature boundary conditions are assigned to both sides of the model, with the annual average temperature at the surface and increase with depth following the geothermal gradient. The heat flow boundary condition is assigned for the bottom boundary. The terrestrial heat flow value is the product of the geothermal gradient times the thermal conductivity of the limestone host rock. According to Fig. 2, we prescribe the variation temperature to the top boundary.

The initial thermal structure is calculated assuming the surface temperature remained constant at the annual average (Fig. 3).

During the simulation, models with phase transition included and phase transition neglected are both calculated for comparison. When phase change is considered, latent heat and the material property variation are considered.

\section{Simulated result and analysis}

\subsection{Evolution of an ice-deposit-forming model}

Because of the periodic change of the ambient air temperature, the temperature in the ice cave will show a periodic variation corresponding to conduction and convective heat transfer. Figure 4a shows the evolution of the temperature at the bottom of the ice cave. It can be interpreted as the process of formation of the cave ice. If a cave was formed but not connected with the outside, it may have a temperature distribution similar to that in Fig. 3. If the cave became connected to the outside, i.e., it collapsed at its top and produced an entrance to the cave, an ice cave would then form within a decade due to the winter convective cooling and would stabilize in a century. Figure $4 \mathrm{~b}$ shows the details of the first two decades and that the calculated results with phase change considered (black line) do not differ significantly from those without considering phase change (red line) in the cooling process. Starting from normal ground temperature, the internal temperature of the ice cave drops rapidly in the first decade, then drops more gradually and finally tends to become stable.

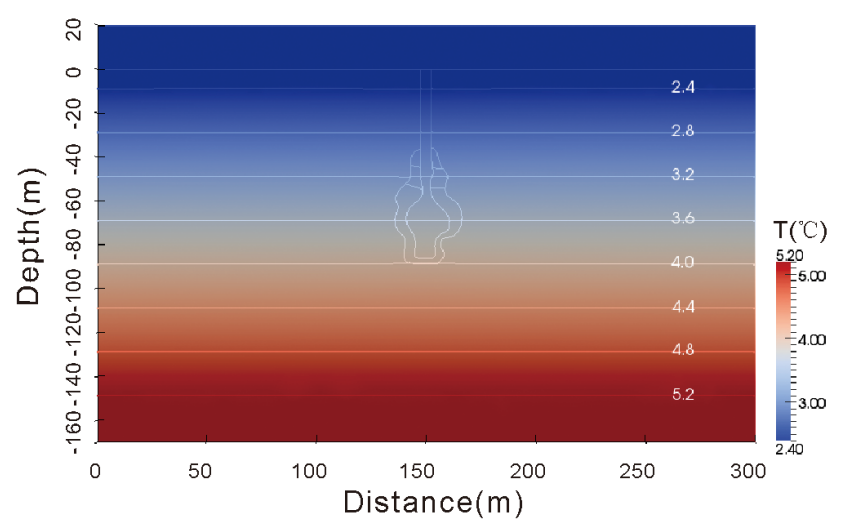

Figure 3. Initial reference temperature distribution around Ningwu ice cave.

Figure $4 \mathrm{~b}$ shows the details of temperature evolving in the ice cave during its initial 16 years of formation. It is seen that the cave ice can be maintained below $0{ }^{\circ} \mathrm{C}$ all year round after winter cooling for about 5 years. The cave temperature increases in spring, summer and fall and decreases in winter, presenting annually periodic variation. The air temperature of Ningwu ice cave decreases rapidly in winter, but the temperature increases slowly in spring, summer and fall because the heat conduction in these seasons is much less efficient than convective heat transfer in winter. With phase change considered (black line), the increased rate of temperature in summer is smaller than that without phase change (red line), because latent heat is required to melt ice near the cave entrance, thus delaying the conduction of heat to the bottom of the cave. In winter, the convective cooling is so effective that the difference is minimized.

Figure $4 \mathrm{c}$ shows the cave temperature annual fluctuations for the case where the process has lasted two centuries, long enough to have evolved to a stable cyclic state. The amplitude of the temperature variation is about $1.0^{\circ} \mathrm{C}$ (from -3.9 to $-2.9^{\circ} \mathrm{C}$ ). Ningwu ice cave has been opened to tourists, so the cave temperature has been disturbed. According to our measurement on 5 June 2012, the lowest internal temperature of the ice cave was $-1.5^{\circ} \mathrm{C}$. Through the record in the literature, the actual measured internal temperature of the ice cave ranges between -1.0 (Meng et al., 2006), -4.0 and $-6.0^{\circ} \mathrm{C}$ (Gao et al., 2005). The difference in measured results may be caused by different measuring methods and different measuring time and positions. Similar to what is shown in Fig. 4b, the cave temperature presents annual periodic variation, and the overall increasing rate of cave temperature is lower than its decreasing rate, because the heat transfer efficiency of conduction is much lower than that of heat convection. The variation in cave temperature for the model with phase change considered (black line) is basically the same as that without phase change considered (red line). The reason is that, although we considered phase change during calculation, the temperature of the ice body in the cave is 

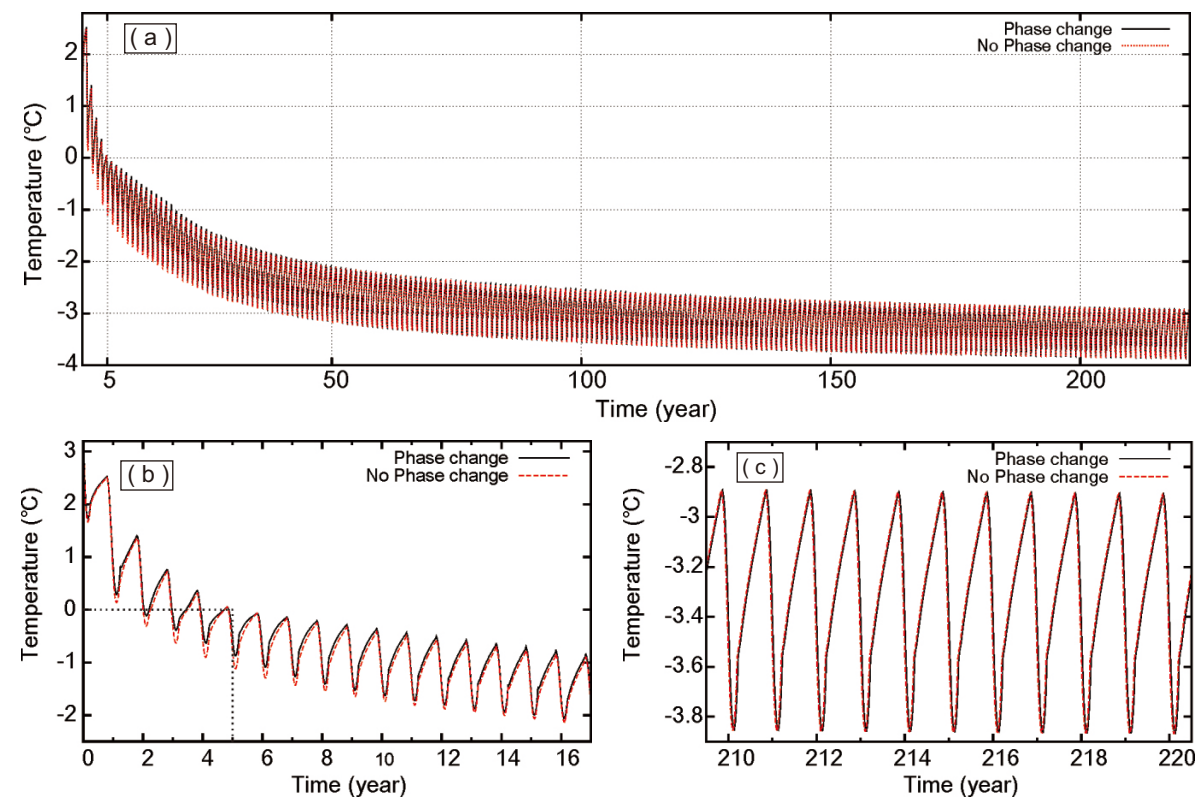

Figure 4. (a) Formation process of Ningwu ice cave, (b) initial formation process and (c) quasi-stable state.

always kept below $0{ }^{\circ} \mathrm{C}$ when it reaches a stable cyclic state and no phase change actually occurs.

Figure $5 \mathrm{a}$ and $\mathrm{b}$ show the spatial temperature distribution around the ice cave in winter and summer, respectively, during the stable stage. Both panels show that a small portion of rock at the top of the ice cave presents a negative geothermal gradient and that most of the host rock presents a normal positive geothermal gradient. Beneath the bottom of the cave, however, geothermal gradients are much higher than normal. The ice body temperature is always kept below $0{ }^{\circ} \mathrm{C}$, although the external temperature is completely different. In Fig. 5a, the temperature of the shallow ground is lower than $0^{\circ} \mathrm{C}$, corresponding to a frozen zone in winter. In Fig. $5 \mathrm{~b}$, the temperature of shallow parts of ground is higher than $0^{\circ} \mathrm{C}$, indicating that the frozen part is melted and there is no permafrost. These features agree with actual conditions.

\subsection{Evolution of an ice-deposit-melting model}

The ice body in the ice cave will melt if there is no air convection heat transfer in winter. With the temperature shown in Fig. 5a taken as an initial temperature, the evolution of temperature distribution will be calculated with or without the phase change effect considered. The results are shown in Fig. 6 as a black line and a red line, respectively. They are the same when temperature does not reach the phase change temperature. The ice body takes much longer to thaw when the latent heat of melting is taken into consideration than when it is not. A complete thaw of the ice body takes 23 years when the latent heat of phase change is not considered, compared with 37 years when it is considered.
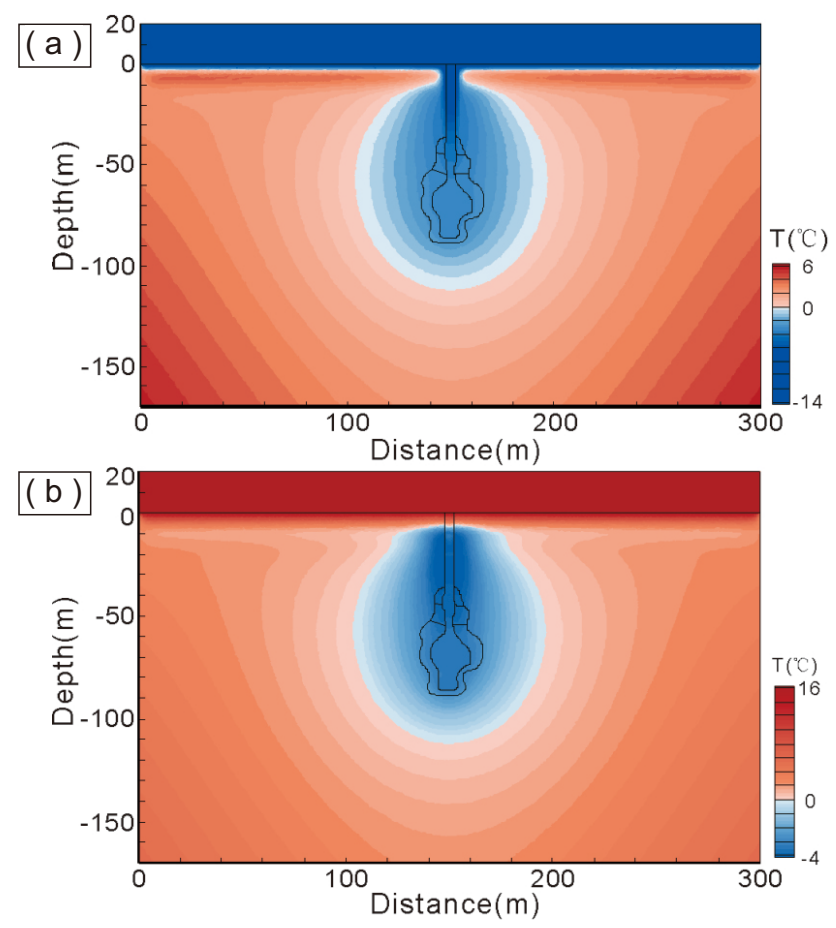

Figure 5. Temperature distribution around Ningwu ice cave in winter (a) and summer (b).

\subsection{Sensitivity to model parameters}

The external air temperature, $N u$ and the number of tourists could directly affect the energy transfer in Ningwu ice cave. Therefore, sensitivity experiments need to be performed for 


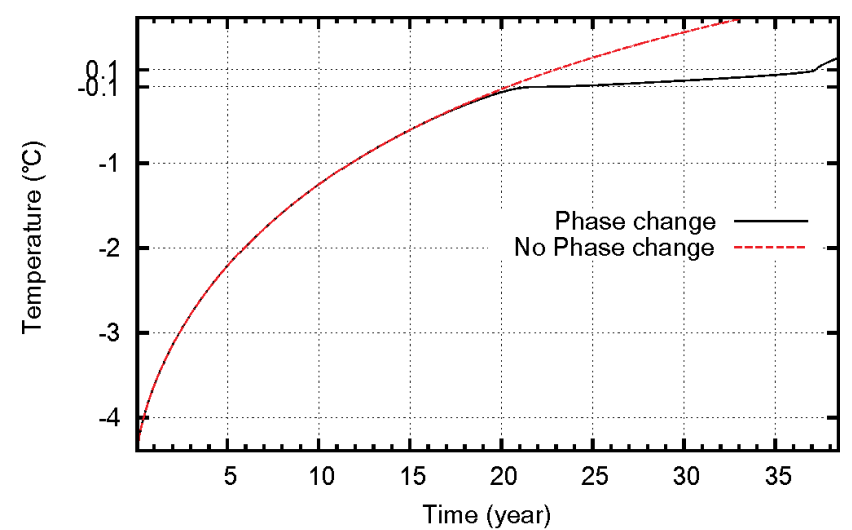

Figure 6. Internal temperature evolution diagram when ice is melting.

these factors. With respect to the external air temperature, we consider two aspects: (1) the mean annual temperature and (2) the amplitude of annual temperature. For the case where the mean annual temperature increases (decreases) by $1.0^{\circ} \mathrm{C}$, the computation results are shown as Fig. $7 \mathrm{a}$ and g (Fig. $7 \mathrm{~b}$ and $h$ ). For the case where the amplitude of external temperature increases (decreases) by $5.0^{\circ} \mathrm{C}$, the computation results are shown as Fig. 7c and i (Fig. 7d and j). For an increase (decrease) in $\mathrm{Nu}$ by $10 \%$, the computation results are shown as Fig. 7e and k (Fig. 7f and 1). About 1000 visitors enter the cave per day from May to October. The heat potentially released by a single person is $840 \mathrm{~J}$. We assume that each visitor spends $1 \mathrm{~h}$ in Ningwu ice cave. Additionally, there are two hundred $15 \mathrm{~W}$ light bulbs. Figure $7 \mathrm{~m}$ shows the computation results for when we consider the number of tourists and light bulbs.

Similar to what is seen in Fig. 4b, Fig. 7a-f show the details of first two decades and indicate that the ice deposit would be formed in Ningwu ice cave within the first two decades in these different experiments. Figure $7 \mathrm{~g}-1$ correspond to Fig. 7a-f. As shown in Fig. 4c, Fig. $7 \mathrm{~g}-1$ depict the cave temperature annual fluctuations for when the process has lasted two centuries, long enough to have evolved to a stable cyclic state. Compared with Fig. 4c, Fig. $7 \mathrm{~m}$ shows that the current density of tourists and number of light bulbs in Ningwu ice cave could not cause the ice deposit to melt. Figure $7 \mathrm{n}$ shows the ice cave temperature annual fluctuations when the mean annual temperature increases by $3.5^{\circ} \mathrm{C}$. We can see the temperature ceiling is $-0.1^{\circ} \mathrm{C}$. We consider this to be the minimum climatic condition required to form Ningwu ice cave.

\section{Discussion}

The age of the cave and that of the ice body are different. The formation of the cave cavity could be old and have taken place in a warmer climate. The formation of the ice body in the cave is a much later process that took place when the bowling-pin-shaped cave was formed and the climate became cold enough. In the present climate, our numerical modeling suggests that the year-round ice body can be formed within a decade.

In spring, summer and fall, air and host rock transmit heat to the ice cave by thermal conduction, increasing the temperature in the ice cave only slightly, since the conduction efficiency is low. In winter, heat is transmitted out of the ice cave by natural thermal convection of air, efficiently decreasing the temperature in the ice cave. Phase change accompanies the thermal processes. Considering these mechanisms, the results show that (1), starting from a normal ground temperature, a year-round ice body will be formed in the cave in less than a decade, about 5 years in our model (Fig. 4b), and the ice cave temperature will decrease continuously for more than a century, and also that (2) the ice cave will finally reach a stable cyclic state and its temperature will fluctuate within a certain range, less than $1.0^{\circ} \mathrm{C}$ (from -3.9 to $-2.9^{\circ} \mathrm{C}$ ) for Ningwu ice cave. At this stage, the annual total heat transferred to the cave by thermal conduction and the heat removed from the cave by convection are balanced.

It would be interesting to further investigate the possibility of imitating nature and constructing a new kind of air conditioning system. At locations with similar climate conditions, people could construct a basement more than $10 \mathrm{~m}$ deep, using natural air convection to freeze ice in the basement in winter and circulate air to the basement for air conditioning in summer.

Installing an airtight door at a cave entrance, as one park has done in China to "protect" the ice cave at night during the tourist season and for the entire winter, when the cave is closed to tourists, actually blocks air convection in winter. As a result, cold air cannot bring out heat from the cave, and accumulation of heat flow from the surface and the deep crust will finally lead to melting of the ice body in the cave. Our computation shows that it takes less than 40 years to completely melt the whole ice body in the cave. This implies that Ningwu ice cave is probably not currently undergoing thawing of the relict ice. This also suggests that scientific management is important for sustainable usage of natural tourism resources. Otherwise, well-meaning acts such as installing a door to completely seal the entrance for protection will actually destroy the natural wonder in a few decades.

\section{Conclusions}

This paper has focused on quantitative analysis of the formation and preservation mechanism of an ice body in Ningwu ice cave, a static ice cave. The finite-element modeling leads to the following conclusion: the controlling factor for forming and sustaining the ice body in the cave is effective cooling of the cave in winter by natural air convection. Heat conduction in spring, summer and fall is very ineffective at warming 

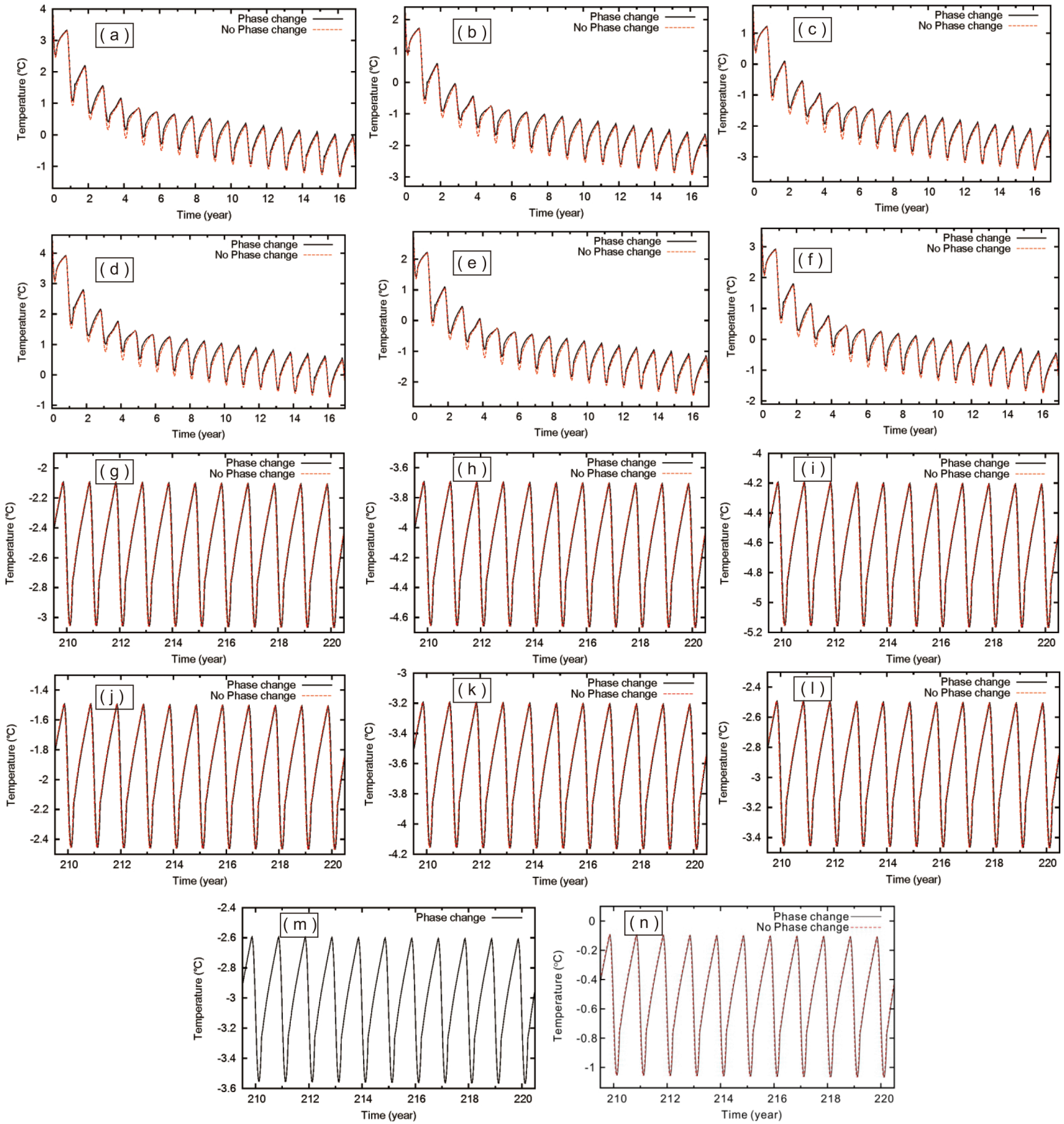

Figure 7. (a-f) Initial formation process of Ningwu ice cave in different sensitivity experiments. (g-l) Corresponding quasi-stable state. (m) Sensitivity experiment featuring density of tourists and light bulbs. (n) Quasi-stable state when the mean annual temperature increases by $3.5^{\circ} \mathrm{C}$.

up the cave. Ice-water phase change further prevents melting of ice in summer. The formation of the cave may take a long geological time, but the formation of the perennial ice body in the cave only takes decades or years under the current temperature and geothermal gradient in the Ningwu area by winter air convection. Once the ice body has formed, the cave temperature will maintain a stable cyclic state. At this time, the amplitude of annual temperature variation in the Ningwu ice cave is within $1.0^{\circ} \mathrm{C}$. Environmental warming even up to $1.0^{\circ} \mathrm{C}$ in the Ningwu area will increase the cave temperature 
but not melt the perennial ice body. The present heat from electric lighting and visitors will not melt the ice body either. However, if the air convective heat transfer is stopped in the winter, as has happened in some other Chinese ice caves, the ice body in the cave could be completely melted within about 40 years. This analysis is important for sustainable management of the ice cave as a tourism resource. The mechanism of ice cave formation may be adopted for construction of energy-saving buildings: ice can be produced in winter in a basement and used for air conditioning in summer.

Acknowledgements. We thank Yong'en Cai and Bojing Zhu for helpful discussions. Constructive comments and suggestions from Stuart A. Harris and an anonymous reviewer significantly improved the quality of this paper. This research is supported by the National Natural Science Foundation of China (NSFC), project 41174067, and the CAS/CAFEA international partnership program for creative research teams (no. KZZD-EW-TZ-19).

Edited by: S. Gruber

\section{References}

Bella, P.: Morphology of ice surface in the Dobšiná Ice Cave, 2nd International Workshop on Ice Caves, Demänovská dolina, Slovak Republic, 2006,

Cebeci, T.: Laminar-free-convective-heat transfer from the outer surface of a vertical slender circular cylinder, Proceedings of the 5th International Conference, Tokyo, Japan, 15-19, 1974.

Chen, S.: Cave Tourism Science, Fujian People's Publishing House, Fuzhou, 2003.

de Freitas, C. and Littlejohn, R.: Cave climate: assessment of heat and moisture exchange, J. Climatol., 7, 553-569, doi:10.1002/joc.3370070604, 1987.

de Freitas, C., Littlejohn, R., Clarkson, T., and Kristament, I.: Cave climate: assessment of airflow and ventilation, Int. J. Climatol., 2, 383-397, doi:10.1002/joc.3370020408, 1982.

Fairchild, I. J. and Baker, A.: Speleothem science: from process to past environments, John Wiley \& Sons, West Sussex, 2012.

Gao, L., Wang, X., and Wan, X.: Analysis of Ice Cave Formation in Ningwu Shanxi, J. Taiyuan Univers. Technol., 36, 455-458, doi:10.3969/j.issn.1007-9432.2005.04.022, 2005.

Gruber, S., King, L., Kohl, T., Herz, T., Haeberli, W., and Hoelzle, M.: Interpretation of geothermal profiles perturbed by topography: the alpine permafrost boreholes at Stockhorn Plateau, Switzerland, Permafrost Periglac. Proc., 15, 349-357, doi:10.1002/ppp.503, 2004.

Holmlund, P., Onac, B. P., Hansson, M., Holmgren, K., Mörth, M., Nyman, M., and Persoiu, A.: Assessing the palaeoclimate potential of cave glaciers: the example of the Scărişoara Ice Cave (Romania), Geografiska Ann. A, 87, 193-201, doi:10.1111/j.04353676.2005.00252.x, 2005.

Hu, S., He, L., and Wang, J.: Compilation of heat flow data in the China continental area (3rd edition), Chinese J. Geophys., 44, 611-626, doi:10.3321/j.issn:0001-5733.2001.05.005, 2001.
Incropera, F. P., Lavine, A. S., and DeWitt, D. P.: Fundamentals of heat and mass transfer, 11th Edn., John Wiley \& Sons Incorporated, Hoboken, NJ, 2011.

Johnson, K. R., Hu, C., Belshaw, N. S., and Henderson, G. M.: Seasonal trace-element and stable-isotope variations in a Chinese speleothem: The potential for high-resolution paleomonsoon reconstruction, Earth Planet. Sc. Lett., 244, 394-407, 2006.

Kenneth, G. L.: The physics of snow crystals, Rep. Progr. Phys., 68, 855-895, 2005.

Lacelle, D., Lauriol, B., and Clark, I. D.: Seasonal isotopic imprint in moonmilk from Caverne de l'Ours (Quebec, Canada): implications for climatic reconstruction, Can. J. Earth Sci., 41, 14111423, doi:10.1139/e04-080, 2004.

Lalkovič, M.: On the problems of the ice filling in the Dobšina Ice Cave, Acta Carsol., 24, 313-322, 1995.

Laursen, L.: Climate scientists shine light on cave ice, Science, 329, 746-747, doi:10.1126/science.329.5993.746, 2010.

Lewis, R. W.: The finite element method in heat transfer analysis, John Wiley \& Sons Inc, Hoboken, NJ, 1996.

Lewis, R. W. and Roberts, P.: Finite element simulation of solidification problems, Appl. Scient. Res., 44, 61-92, doi:10.1007/BF00412007, 1987.

Li, Q.: Some characteristics of the geothermal distribution in ShanXi rift zone, Earthquake research in ShanXi, ShanXi, 2630, 1996.

Luetscher, M., Bolius, D., Schwikowski, M., Schotterer, U., and Smart, P. L.: Comparison of techniques for dating of subsurface ice from Monlesi ice cave, Switzerland, J. Glaciol., 53, 374-384, doi:10.3189/002214307783258503, 2007.

Luetscher, M., Lismonde, B., and Jeannin, P. Y.: Heat exchanges in the heterothermic zone of a karst system: Monlesi cave, Swiss Jura Mountains, J. Geophys. Res., 113, F02025, doi:10.1029/2007JF000892, 2008.

May, B., Spötl, C., Wagenbach, D., Dublyansky, Y., and Liebl, J.: First investigations of an ice core from Eisriesenwelt cave (Austria), The Cryosphere, 5, 81-93, doi:10.5194/tc-5-81-2011, 2011.

Meng, X., Zhu, D., Shao, Z., Yu, J., Han, J., and Meng, Q.: A discussion on the formation mechanism of the "Ten-ThousandYear-Old Ice Cave" in Shanxi Province, Acta Geosci. Sin., 27, 163-168, doi:10.3321/j.issn:1006-3021.2006.02.011, 2006.

Minkowycz, W. and Sparrow, E.: Local nonsimilar solutions for natural convection on a vertical cylinder, J. Heat Trans., 96, 178183, doi:10.1115/1.3450161, 1974.

Morgan, K., Lewis, R., and Zienkiewicz, O.: An improved algrorithm for heat conduction problems with phase change, Int. J. Numer. Meth. Eng., 12, 1191-1195, doi:10.1002/nme.1620120710, 1978.

Obleitner, F. and Spötl, C.: The mass and energy balance of ice within the Eisriesenwelt cave, Austria, The Cryosphere, 5, 245257, doi:10.5194/tc-5-245-2011, 2011.

Perşoiu, A., Onac, B. P., Wynn, J. G., Bojar, A. V., and Holmgren, K.: Stable isotope behavior during cave ice formation by water freezing in Scărişoara Ice Cave, Romania, J. Geophys. Res., 116, D02111, doi:10.1029/2010JD014477, 2011.

Peters, K. F.: Geologische und mineralogische Studien aus dem südöstlichen Ungarn, insbesondere aus der Umgegend von Rézbánya, KK Hof-und Staatsdr., Wien, 1861. 
Roberts, M. S., Smart, P. L., and Baker, A.: Annual trace element variations in a Holocene speleothem, Earth Planet. Sc. Lett., 154, 237-246, doi:10.1016/S0012-821X(97)00116-7, 1998.

Schmeling, H. and Marquart, G.: A scaling law for approximating porous hydrothermal convection by an equivalent thermal conductivity: theory and application to the cooling oceanic lithosphere, Geophys. J. Int., 197, 645-664, doi:10.1093/gji/ggu022, 2014.

Schöner, W., Weyss, G., and Mursch-Radlgruber, E.: Linkage of cave-ice changes to weather patterns inside and outside the cave Eisriesenwelt (Tennengebirge, Austria), The Cryosphere, 5, 603616, doi:10.5194/tc-5-603-2011, 2011.
Shao, Z., Meng, X., Zhu, D., Yu, J., Han, J., Meng, Q., and Lv, R.: Detecation for the spatial distribution of "Ten-Thousand Ice Cave" in Ningwu, ShanXi Province, J. Jilin Univers. (Earth Sci Edn.), 37, 961-966, doi:10.3969/j.issn.1671-5888.2007.05.019, 2007.

Shi, Y. and Wang, C.-Y.: Two-dimensional modeling of the PTt paths of regional metamorphism in simple overthrust terrains, Geology, 15, 1048-1051, 1987.

Sparrow, E. and Gregg, J.: Laminar free convection heat transfer from the outer surface of a vertical circular cylinder, Trans. ASME, 78, 1823-1829, 1956.

Yang, S. and Tao, W.: Heat transfer, 4th Edn., Higher Education Press, Beijing, 2006. 